\title{
An IoT Based Smart Organic Drip Fertigation System for Eco-Friendly Agriculture using SVM Classifier and ThingSpeak
}

\author{
Sujaritha M, Sanjana R
}

\begin{abstract}
In agriculture, large-scale farming and feeding of effective organic nutrients to plants, in wide-ranging irrigation field becomes a serious scenario faced by majority of sectors in present agricultural system. In present, adapting the method of irrigation and continuous monitoring of irrigation system in agricultural field is becoming difficult for the farmers in adverse situations. The main intention of this paper is to feed the crops with organic nutrient content and to automate the continuous monitoring of water level, temperature, salt content present in water using Internet of Things (IoT). An IOT based Organic Drip Fertigation system mainly helps the farmers to automatically sense the difficulties that may occur due to the presence of salt content in water also automates fertigation method (the usage of organic nutrients) to make comparatively high yield than the ordinary methods. As a result, the proposed system helps in reducing soil erosion as only the required nutrients are injected via the drip system in order to reduce the usage of chemical fertilizers. In this paper, we use Support Vector Machine (SVM) to classify three (Temperature, Ph, Flow) feature vectors. The classification results will predict whether the obtained data is normal or abnormal and explore the accuracy of classification prediction by using SVM. Finally, the classification result obtained by applying SVM is uploaded to the ThingSpeak cloud.
\end{abstract}

Keywords: Fertigation, Irrigation, soil erosion, SVM, ThingsSpeak.

\section{INTRODUCTION}

India ranks second among agricultural country with plenitude of fertile lands. Irrigation is an essential means of watering land to make it ready for agricultural purposes. An irrigation system is the main means of supplying water via artificial canals and channels to growing plants and crops in a field. Drip Irrigation system is one of the predominant aspects to be enriched meeting the economic and sustainable challenges of the farmers. The combination of agriculture and IOT domain, helps the farmers to easily detect the problems occurring in the field. Thus, preventive measures can be done in advance so that it safeguards the field from causing any destructions.

Revised Manuscript Received on April 02, 2020.

* Correspondence Author

DR. M.Sujaritha*, Professor, Department of Computer Science \& Engineering, Sri Krishna College of Engineering and Technology, Coimbatore, India. Email: sujaritham@skcet.ac.in

R. Sanjana, Department of Computer Science \& Engineering, Sri Krishna College of Engineering and Technology, Coimbatore, India. Email: 18epcs003@skcet.ac.in

(C) The Authors. Published by Blue Eyes Intelligence Engineering and Sciences Publication (BEIESP). This is an open access article under the CC BY-NC-ND license (http://creativecommons.org/licenses/by-nc-nd/4.0/)
Farmers are facing difficulties to manage all the field activities like feeding crops, measuring PH, Temperature etc. manually for large farming agricultural. All the data is collected using the smart Fertigation system and SVM classifier is applied and the yield rate is predicted, also day to day obtained data is stored in ThingSpeak cloud storage.

In olden days to increase the yields and better quality of crops, farmers use either water soluble fertilizer or other organic fertilizer to feed the plants. But in present there comes a modern innovative technique, that provides an excellent method to maximize yield rate of the crop and to minimize the use of chemical substances as it leads to environmental pollution thereby feeding organic nutrient to plants called "Fertigation". Fertigation is a process in which fertilizer is dissolved and distributed along with irrigation water by the drip system to the crops in the field. Nutrients (Jeevamrutham and Panchakavya) are applied to the root zone of the crop and uniformly sprinkled to the entire agricultural field through drip fertigation method. Thus, this method strengthens the fertility of agricultural land also sustained crop growth is obtained and yield rate of the crop percentage is increased by $90 \%$ field, also leads to high labor cost. To overcome this phase, an IOT based smart drip fertigation system is developed for the continuous monitoring and it senses the temperature, water PH and Nutrient content flow.

\section{ORGANIC NUTRIENTS}

1. Nutrients is any substance that is absorbed by the crop or agricultural field and it plays a vital role in the farming field. It provides vitality or empowers development, also it feeds proper enhancement for plant yield.

2. In this study of Indian method fertigation, two types of nutrients are used "Jeevamrutham" and "Panchakavya".

3. Jeevamrutham is an organic manure that is used to improve soil fertility and microbial activities in soil. It is made by mixing cow dung, cow urine (of native cows) along with a few other ingredients and fermenting them. Jeevamrutham hastens the natural functions of the soil there by increasing the growth rate of plants and their yield. Earthworm, inevitable to the fertility of soil moves up towards the top as a result of this. The elements in the excreta of earth worm, is broken down into molecular form by the microbes in the Jeevamrutham, so that,

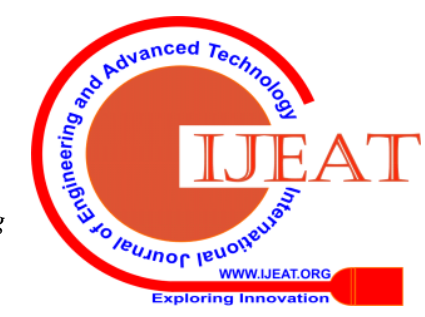




\section{An IoT Based Smart Organic Drip Fertigation System for Eco-Friendly Agriculture using SVM Classifier and ThingSpeak}

it can be easily absorbed by the roots. These microbes disintegrate wastes in the soil there by making soil more fertile. The upward and downward movement of the worms loosens up the soil. This creates a positive environment for the growth of the plants. It also helps plants to absorb nutrients from the soil and it reduces the soil pollution.

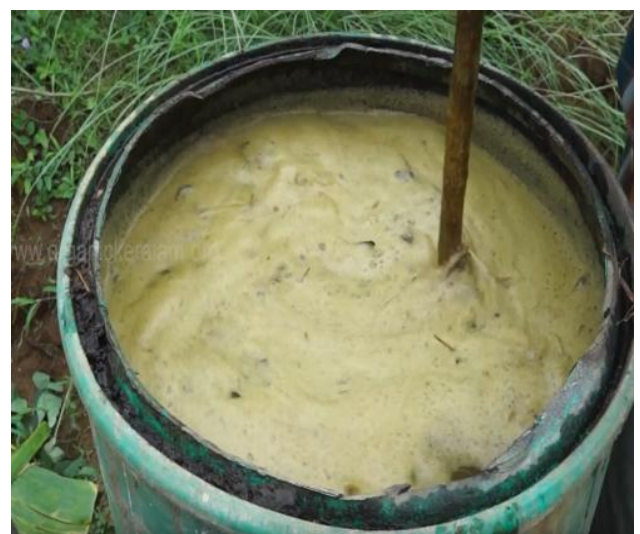

Fig 1. Organic nutrient Jeevamrutham

Panchagavya is one of the most essential organic products which helps the agriculture field to improve the promoting growth and providing immunity to crops and soil in irrigation system. By increasing the immunity, the crops in the field will be able to resist the occurrence of pests and other diseases caused by them. Also, it improves water holding capacity in the agricultural field because it acts as an organic manure. Panchagavya contains major nutrients that is the main enhancement of growth hormones like IAA \& GA required for crop growth i.e. macronutrients like nitrogen, potassium etc. and micronutrients which are required for the growth and development of plants and also contains different types of amino acids. The existence of microorganisms like fungus, yeast and bacillus might occur due to the available mixtures like dairy products and addition of jaggery as substrate will help in strengthening the roots for their growth. No chemicals are used in the preparation method also it provides eco-friendly approach. Thus, in this project we use Panchagavya to increase the concern for environmental safety and to minimize the usage of other unwanted chemical fertilizers.

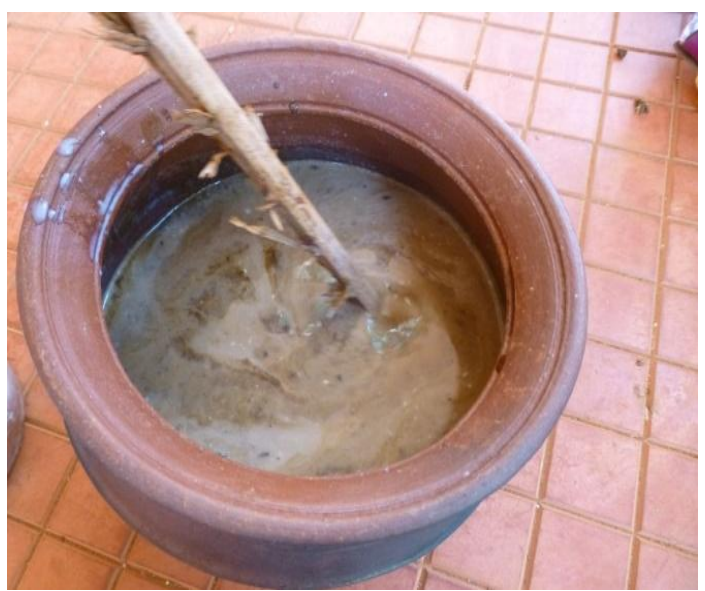

Fig 2. organic nutrient Panchagavya

\section{LITERATURE SURVEY}

In this section, a survey has been conducted on drip irrigation and fertigation methods.

Irrigation system movements inside the most recent 3 decades have been astonishing. Micro irrigation type of system scale is one of the latest headways for applying water and it speaks to a positive enhancement in water system innovation. It very well may be described as successive use of little amount of water legitimately, finished or underneath the dirt surface. Sorts of smaller scale water system frameworks join surface dribble, subsurface trickle, sprinkle water system and bubbler water system. The surface trickle consolidates both online dribble framework and crucially dribble line structure. Fertigation notwithstanding sparing of composts likewise allows applying manure in little amounts as indicated by the plant's supplement prerequisites. It is additionally considered eco-accommodating as it preserves draining of chemical substance use.

Practice of trickle fertigation brought about reserve funds of manures over surface telecom viz., $20 \%$ in banana, half in sugarcane, $40 \%$ in potato, and $50 \%$ in onion. Likewise, Neelam Patel and Rajput (2001) revealed compost investment funds of $40 \%$ manures when contrasted with the telecom technique for compost application without influencing the harvest yield in bhendi.

Patil et al, has built up a shrewd water tank the board framework worked with mega 128A microcontroller, which was the fundamental segment of their framework. Right now, intercession won't be required for nonstop water supply. They have been utilizing a microcontroller, a store, water tank and water siphon. Water siphon utilizes hand-off and contact sensor to control. Six custom made contact sensors are utilized (three for each tank) are used to distinguish a degree of water. The reenactment of the whole framework is done in Proteus V7.2 programming. They have utilized WinAVR's Programming Notepad programming for the code reproduction. This framework can be utilized in some other liquids in synthetic enterprises or processing plants.

\section{A. Eco-Friendly Agriculture using Drip Fertigation}

Numerous reports have referred to and condensed potential effects of fertigation in trickle water system contrasted with different techniques. An endeavor has been made to talk about the writing relating to the effect of selection of surface trickle on crop yields, water, force and compost reserve funds; and financial matters just, since the majority of the zone secured under Andhra Pradesh Micro water system framework was under dribble water system.

In creating nations there is proficient strategy to apply fertigation as a method for ecologically benevolent composts application. Soil is a key segment in fertigation as it can cause achievement or disappointment on the off chance that it isn't considered appropriately. Soil parts which ought to be assessed before use of fertigation include: Soil suddenness content similarly as holding limit, Oxygen framework, Soil surface and infiltration rate, salt substance in soil, Available enhancements in the earth similarly as alkalinity and causticity. 
Soil surface will coordinate the maker's stream rates and division between them, when fertigation is done using trickle arrangement of water system.

\section{PROPOSED SYSTEM}

The system is developed in the way that it allows farmers to interact with the automatic fertigation system using the web or mobile phones. An approach on automatic feeding of organic nutrients through drip irrigation can be automated using the sensors and water level indicator, which helps to notify the amount of nutrients that is consumed by crops in daily bases. The automation is done in such a way that the injected nutrient content in water should be consumed by the crops for every 2 days in a week and the report is to be generated to the farmers or users through messages. Also, it should ensure whether the salt content in the water is blocking the nutrient contents reaching the crop, if it disallows the nutrient contents then an alarm or message is intimated to the user. All these data are recorded in the regular bases and saved in the ThingSpeak cloud. Thus, the system is very useful for the farmers to monitor and manage their farms by using mobile devices, at anywhere and anytime.

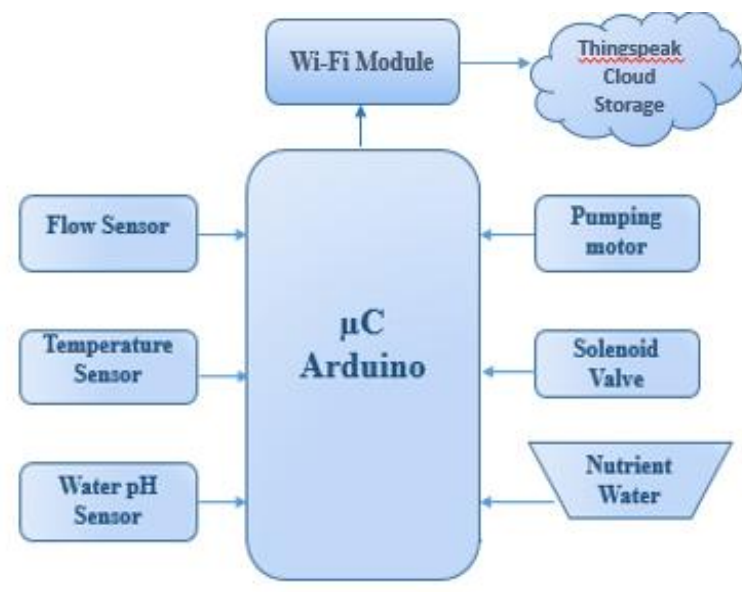

Fig 3. System Architecture

The Arduino board is connected to a laptop by using USB, where it connects with the Arduino development environment (IDE). The person writes the Arduino code in the IDE, then uploads it to the microcontroller which compile and executes the code, interacting with the given inputs and it produces the outputs of sensors and motors. Also, the data is transmitted to WI-FI module (ESP8266) and using SVM classifier algorithm it classifies the value of temperature, $\mathrm{PH}$ content and the nutrient flow of water and they are uploaded in ThingSpeak.

\section{RESULTS AND DISCUSSION}

In the agriculture field area, the smart organic drip fertigation setup is made. The data obtained from all the sensors are sent to the Arduino contoller. Flow sensor is fixed in the drip system is a simple method, which helps the user to easily control the water flow using this device and it intimates the farmer whether the flow of the nutrient content is normal or abnormal.
The $\mathrm{pH}$ (always written little $\mathrm{p}$, big $\mathrm{H}$ ) of a substance of how many hydrogen ions in a certain volume of water. ' $\mathrm{pH}$ ' stands for potential of hydrogen. In this system the $\mathrm{PH}$ level is estimated using the sensor and it also detects due to the salt content flow of the water is restricted or not. The agricultural production requires large volumes of water. It consumes large quantities of electricity, for electrical pumps, to move the full-size volumes of water needed for drip irrigation purposes. The pumps have the capacity to transfer clear water, chemical, fertilizer and nutrients to the crops in the field. Solenoid valves usage in agriculture is to switch on and off the gadget. It mainly manipulates gadgets which, when electrically energized or de-energized, either shut off or enable fluid flow. The actuator takes the structure of an electromagnet. When energized, a magnetic area builds up which pulls a pivoted armature against the motion of a spring. All the data obtained is manipulated and the result is obtained in ThingSpeak in a graphical format.

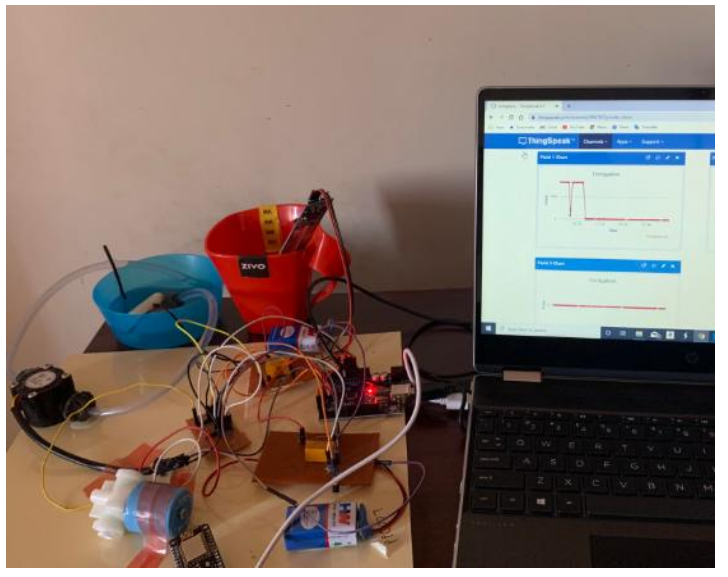

Fig 4. Experimental Setup

\section{A. Support Vector Machine Classification}

SVM is fundamentally a two-class classifier dependent on the possibility of "huge edge" and "mapping information into a higher dimensional space". The rule of SVM is to make limit the organized hazard, in the high dimensional element space, locate an ideal discriminant hyperplane with low VC measurement to cause the separation between the two classes' information to have an enormous edge, the bigger the edge hyperplane, the better the grouping. In the event that component estimation of information is direct indivisible, SVM maps the information into high dimensional element space with non-straight mapping and finds the ideal characterization hyperplane in high dimensional element space. Parameters from the temperature, $\mathrm{PH}$ and flow sensor are collected and accuracy is estimated using SVM. The obtained result is tabulated below:

Table- I: SVM Accuracy Results

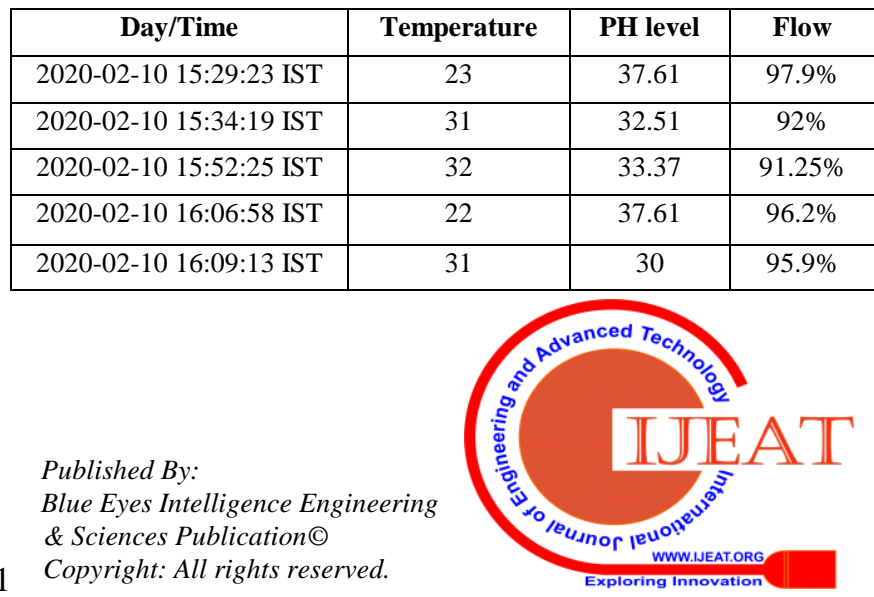




\section{An IoT Based Smart Organic Drip Fertigation System for Eco-Friendly Agriculture using SVM Classifier and ThingSpeak}

\section{B. ThingSpeak}

ThingSpeak Cloud platform is an IOT based analytical platform where the sensed data are lively udated in the cloud for every water flow. The values are analyzed and they are plotted accordingly in ThingSpeak cloud with respect to date and time, also it will help us to execute the data analytics in MATLAB code and day to day activities are updated.

- In the first instance, we have to join in thingspeak iot web page by giving our credentials and later we have to make channel on it reliant on our endeavor title.

- we can associate with the Aurdino which is available in the hardware through WI-FI ESP8266 module.

- The accurate values obtained from SVM classifier is sent to the ThingsSpeak cloud through wireless network and the final result is plotted in a graph and displayed in our own private channel in ThingSpeak web page.

The obtained results in ThingSpeak webpage is displayed below:

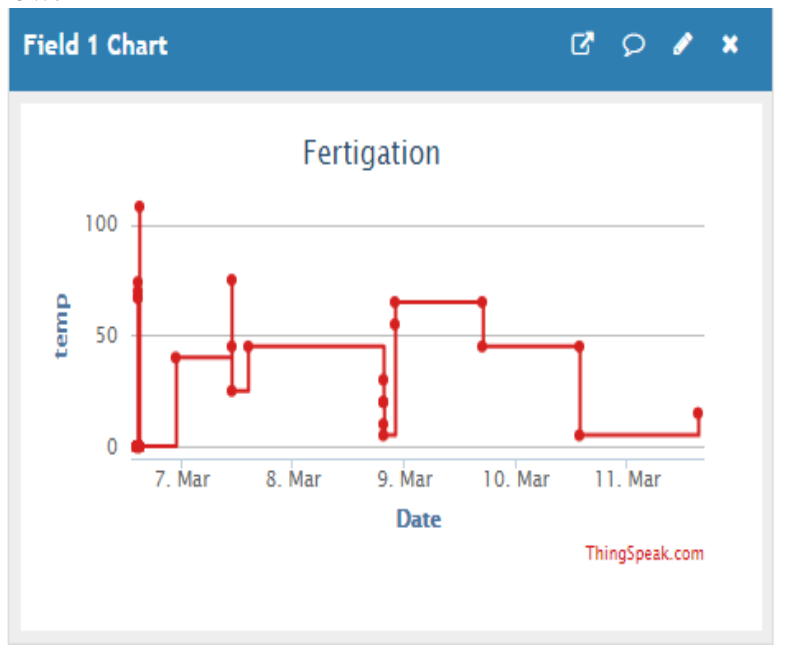

Fig 5. Temperature level prediction

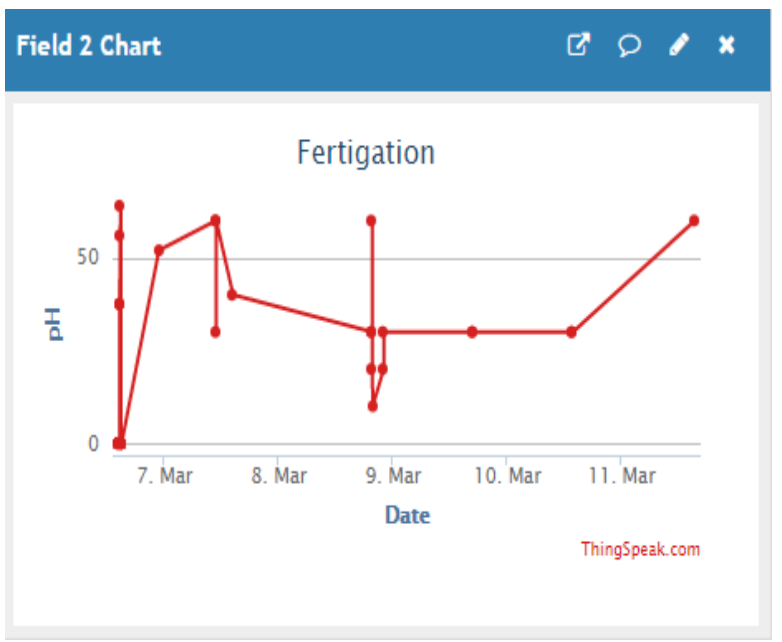

Fig 6. Water $\mathrm{PH}$ content results

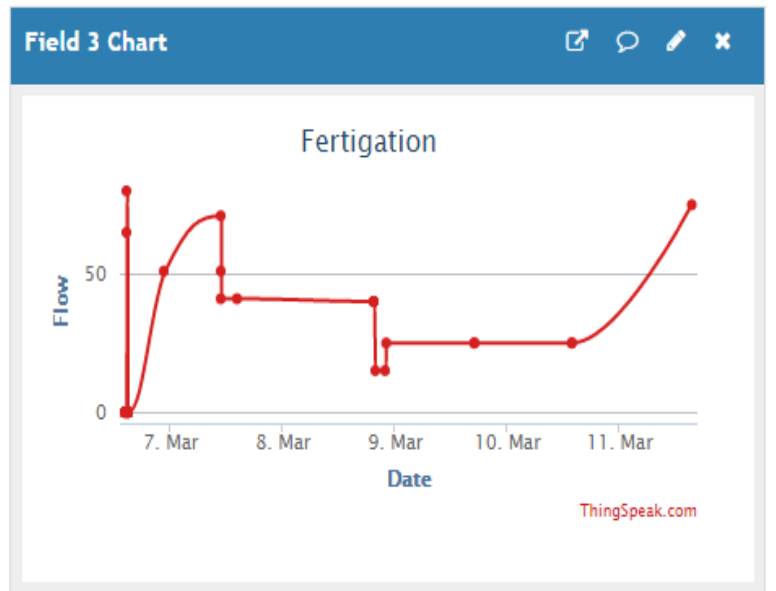

Fig 7. Nutrients containing water flow results

\section{CONCLUSION}

Since both fertigation and drip system framework are the most significant factors in cultivating. Fertigation is truly outstanding and economically beneficial and it ought to be made broad in creating nations. With one-time funding on essential basic equipment, farmers can save money on work, time, cash and in addition, they can understand higher yield in collect as the fertigation framework gives supplements in a reasonable manner.

Farmers have to be trained to this system by conducting agricultural welfare inauguration and fertigation farming machine need to also be given to motivate the producers by way of advertising these products to the farmers and practical session should be conducted in phrases of environmental benefits. The major impact of adopting fertigation in drip irrigation allows us to save electricity and also reduces the manual intervention.

This proposed system mainly focuses on the feeding of organic substances (Jeevamrutham and Panchakavya) through drip irrigation by fertigation process. The usage of this method helps to strengthen the crop and improves the irrigation efficiency. The exact dosage of nutrient content to the crops are tracked in the regular basis also it ensures the soil erosion. Also, this fertigation system is useful because it helps the farmers to maintain the entire farm without causing damage to the crops and in increasing the overall yield and the results are updated in ThingSpeak. The proposed system mainly preserves water than all the traditional irrigation methods by ensuring the optimal growth in low cost, high reliability, highly effective and accuracy.

\section{REFERENCES}

1. Hemlata Channe, Sukhesh Kothari, Dipali Kadam, "Multidisciplinary Model for Smart Agriculture using Internet-of-Things (IoT) Sensors Cloud-Computing Mobile-Computing \& Big-Data Analysis", Int.J Computer Technology \& Applications, vol. 6, no. 3, pp. 374-382, 2015.

2. Yao Zhouhua, Wei Xinhua, ZuoZhiyu, Zou Sheng, Mao Hanping, "Development of Working Status Monitoring Device for Automatic Fertigation System", Transaction of the CSAE, vol. 31, pp. 45-47, Oct. 2012

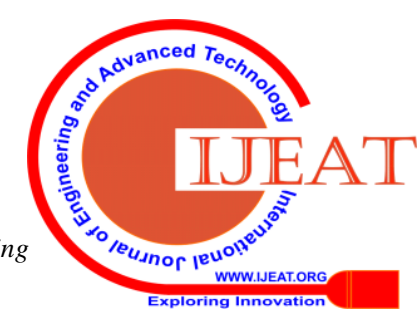


3. Vimal.P, Priyanka.V, Rajyasree.M, S. Devi.P.T, Jagadeeshraja.MAnd S. Vanitha.N, "A Novel Approach for Automatic Irrigation and Fertigation Using Embedded System," International Journal of VLSI and Embedded Systems-IJVES, vol. 5, no. 03257, 2014.

4. Real time implementation of a GSM based Automated Irrigation Control Sy stem using drip", Irrigation Methodology, vol. 4, no. 5, May 2013.

5. Sulochanamma B N, Reddy T Y, Reddy G S, 2005. Effect of basin and drip irrigation on growth, yield and water use efficiency in pomegranate cv. Ganesh Acta-Horticulturae. 2005; (696): 277-279.

6. Swarajya Lakshmi K, Muni Reddy D, Shiva Shankar M, Suresh Babu K and Nageswara Rao P, 2005. Studies on Response of Chilli to different levels of Drip irrigation and mulching as compared to basin method of irrigation ICPPF/253/M1/D/42 : 2005 - 231.

7. Smika D E, Heermann D F, Duke H R, Bathchelder A R (1977). Nitrate Percolation through irrigated sandy soils as affected by water management. Agronomy Journal. 69(4), 623-626.

8. Imas, P. and Price, M. (2008) Fertigation: Optimizing the Utilization of Water and Nutrients. Fertigation Proceedings: Selected Papers of the IPI-NATESC-CAUCAAS International Symposium on Fertigation, Beijing, 20-24 September 2005.

9. Jones Jr, J.B. (2012) Plant Nutrition and Soil Fertility Manual. CRC Press, Boca Raton. https://doi.org/10.1201/b11577.

10. Neelam Patel and Rajput T B S, 2001. Effects of fertigation on growth and yield of onion (Allium cepa), Microirrigation: (Eds. Singh H. P., S. P. Kaushish, Ashwani Kumar, T. S. Murth, Jose C. Samuel).

11. Patil, Yogita, and Ramandeep Singh. "Smart water tank management system for residential colonies using Atmega128A microcontroller." Int J SciEng Res 5.6 (2014): 335-337.

12. Sivanappan R K, 1987. Use of plastics in agriculture - Status and prospects of drip irrigation in India. Proceedings of National Seminar, New Delhi.

\section{AUTHORS PROFILE}

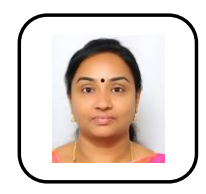

M. Sujaritha currently working as Professor in Department of Computer Science and Engineering, Sri Krishna College of Engineering and Technology, Coimbatore. And, completed Ph.D in Anna University, PG Graduation in Bharathiar University and have experience for 17 years in teaching. Area of interest in Artificial Intelligence and Machine Learning. Published more than 59 papers in national and international journals and conferences and 3 patents. Achieved Outstanding research paper award from Nature Science Foundation in 2018. Associate Member in "The Institution of Engineers (India)", Life Member in "The Indian Society for Technical Education", and Member in "Editor- AI in Agriculture (Elsevier, Science Direct)".

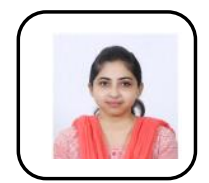

R. Sanjana pursing Master's in Computer Engineering Sri Krishna College of Engineering and Technology, Coimbatore and completed B.Tech IT from Sri Krishna college of Technology. Published a paper on "A Survey on Prediction of Heart Diseases Using Big Data Algorithms" in the International Journal of Advanced Research in Computer Engineering \& Technology.

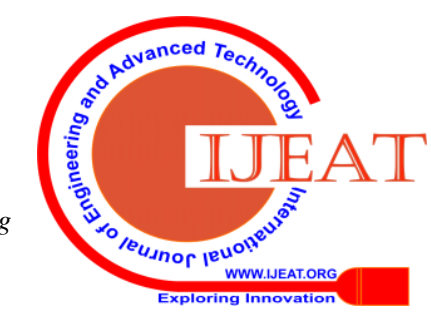

